\title{
Tobacco litter costs and public policy: a framework and methodology for considering the use of fees to offset abatement costs
}

\author{
John E Schneider, ${ }^{1,2} \mathrm{~N}$ Andrew Peterson, ${ }^{3}$ Noemi Kiss, ${ }^{4}$ Omar Ebeid, ${ }^{4}$ Alexis S Doyle ${ }^{5}$
}

${ }^{1}$ Health Economics, Oxford Outcomes, Inc., Morristown, New Jersey, USA

${ }^{2}$ Department of Economics, Drew University, Madison, New Jersey, USA

${ }^{3}$ School of Social Work, Rutgers University, New Brunswick, New Jersey, USA

${ }^{4}$ Oxford Outcomes, Inc., Morristown, New Jersey, USA ${ }^{5}$ Department of Economics, University of Massachusetts, Boston, Massachusetts, USA

\section{Correspondence to}

Dr John E Schneider, Health Economics, Oxford Outcomes, Inc., 161 Madison Avenue, Suite 205, Morristown, New Jersey 07960, USA; john. schneider@oxfordoutcomes. com

Received 15 November 2010 Accepted 12 March 2011

\section{UNLOCKED}

This paper is freely available online under the BMJ Journals unlocked scheme, see http:// tobaccocontrol.bmi.com/site/ about/unlocked.xhtml
ABSTRAC

Objectives Growing concern over the costs, environmental impact and safety of tobacco product litter (TPL) has prompted states and cities to undertake a variety of policy initiatives, of which litter abatement fees are part. The present work describes a framework and methodology for calculating TPL costs and abatement fees.

Methods Abatement is associated with four categories of costs: (1) mechanical and manual abatement from streets, sidewalks and public places, (2) mechanical and manual abatement from storm water and sewer treatment systems, (3) the costs associated with harm to the ecosystem and harm to industries dependent on clean and healthy ecosystems, and (4) the costs associated with direct harm to human health. The experiences of the City of San Francisco's recently proposed tobacco litter abatement fee serve as a case study.

Results City and municipal TPL costs are incurred through manual and mechanical clean-up of surfaces and catchment areas. According to some studies, public litter abatement costs to US cities range from US\$3 million to US\$16 million. TPL typically comprises between $22 \%$ and $36 \%$ of all visible litter, implying that total public TPL direct abatement costs range from about US\$0.5 million to US\$6 million for a city the size of San Francisco. The costs of mitigating the negative externalities of TPL in a city the size of San Francisco can be offset by implementing a fee of approximately US\$0.20 per pack. Conclusions Tobacco litter abatement costs to cities can be substantial, even when the costs of potential environmental pollution and tourism effects are excluded. One public policy option to address tobacco litter is levying of fees on cigarettes sold. The methodology described here for calculating TPL costs and abatement fees may be useful to state and local authorities who are considering adoption of this policy initiative.

\section{INTRODUCTION}

An 'externality' occurs whenever the activities of one economic agent affect the activities of another agent in ways that are not taken into account by the operation of the market. When these activities are harmful to one of the economic agents, and the harmed agent is not compensated for the harm, the cause of the harm is typically referred to as a negative externality. ${ }^{1-3}$ Litter is considered a negative externality in that the market prices for litter-producing products generally do not reflect the costs incurred by third parties for the management and disposal of litter-a direct byproduct of consumption of the product. A variety of taxes and fees can be levied to compensate for the costs of negative externalities; for example, the use of tobacco taxes to offset the negative health effects of smoking. Another negative externality associated with tobacco-the generation of tobacco product litter (TPL)-is generally not considered when implementing tobacco taxes, and can be viewed as an uncompensated tobacco-related negative externality. ${ }^{2}$

More than 360 billion cigarettes were consumed in the US in $2007 .{ }^{4}$ While many cigarette smokers dispose of their cigarette-related litter properly, it is inevitable that others will not, thereby resulting in the littering of cigarette butts and other tobaccorelated packaging. ${ }^{5}$ For example, in an observational study of 9757 individuals in 130 locations in the US, researchers observed a $45 \%$ littering rate for cigarettes. ${ }^{6}$ According to an extensive annual worldwide litter audit performed by the Ocean Conservancy, TPL comprised $28 \%$ of all litter collected from beaches and coastal areas. ${ }^{7}$ TPL has been shown to be toxic, slow to decompose, costly to manage and growing in volume-a trend that appears to be exacerbated by the increased prevalence of indoor smoking bans. ${ }^{8-11}$

Growing concern over TPL has prompted some cities to undertake a variety of policy initiatives. ${ }^{12}$ Novotny et al summarises the problem as follows: 'Carried as runoff from streets to drains, to rivers, and ultimately to the ocean and its beaches, cigarette filters are the single most collected item in international beach cleanups each year. They are an environmental blight on streets, sidewalks and other open areas'. ${ }^{12}$ The authors suggest a variety of policy options to address the problem, including developing biodegradable filters, increasing fines and penalties for littering butts, monetary deposits on filters, increasing availability of butt receptacles, assessing fees to cover the public costs of TPL abatement and expanded public education.

In this paper, we put forth a framework and method that can be used to identify and calculate the costs of TPL abatement to cities, and we describe how this approach can be used to determine the need for public policy that implements fees to offset the costs of the negative externality posed by TPL. As an example, we discuss the case of San Francisco, California, which recently commissioned a study of TPL costs to the City that applied this framework and methodology and, as a result of the analysis, proposed a per-pack abatement fee based on estimated TPL costs. ${ }^{13}$ Because this area of research and policy is largely 
underdeveloped, and consequently there is a paucity of peerreviewed resources from which to draw upon for evidence, this research was needed to develop a conceptual and methodological foundation upon which to build an empirical literature on the costs of TPL as an uncompensated tobacco-related negative externality.

\section{Conceptual model}

The development of a methodology for studying TPL costs to a city, county or state requires a framework that considers the sources and accumulation of TPL and how these produce direct and indirect costs (figure 1). Cigarette butts and other TPL, when disposed of improperly, are typically dropped, flicked or flushed into streets, sidewalks, parks, toilets and so on. Following disposal, TPL either accumulates in the vicinity of disposal or migrates to other areas through gutters, culverts, and drainage and sewage systems. TPL abatement includes the collection of litter at or near the source using a combination of manual clean-up, mechanical street/sidewalk sweeping and power washing. TPL abatement is also necessary at centralised accumulation sites, such as storm drains, sewers and treatment plants. Mitigation at centralised sites includes storm drain clean out, sewer clean out (eg, cleaning debris screens and filters at sewage treatment plants) and others forms of manual clean up.

The total direct costs of TPL abatement $\left(\mathrm{TC}_{\mathrm{TPL}}\right.$ ) is primarily associated with mechanical and manual abatement from streets, sidewalks, parks and other public places, storm water and sewer treatment systems. ${ }^{14-16}$ These activities are typically carried out by departments of public works, parks and recreation, transportation, and public utilities. Total abatement costs are primarily a function of the amount of accumulated TPL ( $\mathrm{Q}_{\text {TPL }}$ ), the average unit costs of abatement activities $\left(\mathrm{AC}_{\mathrm{TPL}}\right.$, which, for example, can be thought of as cost per cubic meter of litter collected) and the desired level of clean-up effort $(\alpha)$. Thus, total public abatement costs can be expressed as $\mathrm{C}_{\mathrm{TPL}}=\alpha$ $\left(\mathrm{AC}_{\mathrm{TPL}} \times \mathrm{Q}_{\mathrm{TPL}}\right)$ where $0 \leq \alpha \leq 1$. The indirect costs of TPL include harm to businesses, tourism, ecosystems and human health. ${ }^{11} 12$ 17-29

\section{METHODS}

There are several ways in which the components of $\mathrm{C}_{\mathrm{TPL}}$ can be measured, and each of these approaches is associated with a set of tradeoffs. To begin, we assume that a city or municipality establishes as its objective to clean up all litter, such that $\alpha=1$. This assumption implies that the total costs of TPL abatement is a function of the total units of litter and the abatement costs per unit of litter (ie, $C_{T P L}=f\left(A_{T P L}, Q_{T P L}\right)$ ). The following sections provide an exploratory discussion of methods to measure TPL quantity and TPL abatement costs, and how those components can be used to develop an externality-based fee.

\section{Quantity}

There are several options for measuring the amount (or share) of TPL in a city or municipality. In this article, we focus on two options-one based on data from litter surveys and the other based on data on tobacco sales. Litter surveys have been conducted in several cities and some cities conduct annual or periodic surveys of litter employing a consistent methodology over time. Surveys of 'visible' litter can be used to generate an estimate of the percent of all litter that is TPL (for convenience we hereafter refer to this percentage as $\lambda$ ). According to an extensive literature review conducted by RW Beck and Keep America Beautiful $(\mathrm{KAB})^{16}$, litter studies conducted in the past decade have reached remarkably similar findings, with $\lambda$ estimates ranging from $23 \%$ (Toronto) to $37 \%$ (Iowa), ${ }^{16}$ and a national survey of visible litter by $\mathrm{KAB}$ found that cigarette butts comprise $36 \%$ of all visible litter. ${ }^{30}$ In addition, as reported earlier, coastal clean-up studies, such as the annual survey conducted by the Ocean Conservancy, generate TPL estimates falling in the range of urban visible litter studies $(28 \%$ in the most recent survey for which data are available). ${ }^{7}$ The attractiveness of this approach is that it offers a means to 'weight' aggregate department-level litter abatement cost estimates, resulting in a share of total litter costs that are attributable to TPL.

An alternative approach to estimating TPL quantity is to adjust cigarette sales data for the propensity for tobacco products to be disposed of improperly. Earlier, we cited a study by Action Research and $\mathrm{KAB}$, which conducted a survey of 9757 individuals in 130 different locations nationwide. The study found that TPL was associated with a $65 \%$ littering rate. ${ }^{31}$ For the 360 billion cigarettes sold in the US, this littering rate would result in 234 billion cigarette butts disposed of improperly. The limitation of this approach is that it is difficult to link the result with abatement costs because city departments do not generally track litter costs by the amount or volume of litter, particularly specific kinds of litter.
Figure 1 Conceptual models of sources, accumulation, abatement methods and public costs of tobacco product litter (TPL).

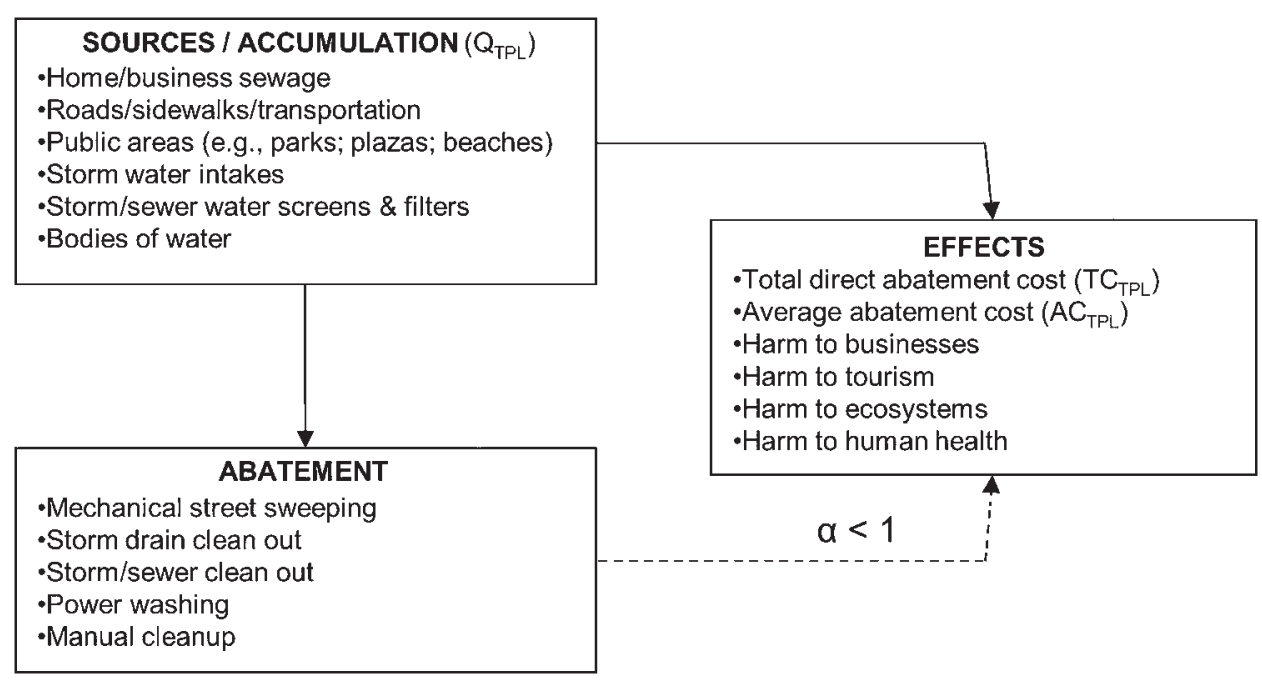




\section{Abatement costs}

There are two primary challenges in measuring the costs of TPL abatement. First, cities do not generally account for TPL abatement costs distinct from aggregate litter abatement costs. Second, departments charged with litter abatement do not typically link their efforts to a specific volume or weight of litter, whereby a department would be able to report, for example, cost per cubic meter of litter collected. However, cities do in most cases cities do account separately for aggregate litter and clean-up activities as distinct from other public works functions (see, eg, Keep America Beautiful, Beck RW ${ }^{16}$, Keep America Beautiful, MSW Consultants ${ }^{30}$, City of Baltimore ${ }^{32}$ and Pitfield and Rathbone ${ }^{33}$ ). These estimates are typically based on cost reports surveyed or collected from the departments responsible for the bulk of litter abatement activities; for example, public works, parks and recreation, port commissions and authorities, municipal transportation authorities, and public utility commissions. Some estimates of the total costs to cities of litter abatement range from US\$2.90 per capita (about US\$3 million for a city with 1 million residents) to US $\$ 5$ million (Baltimore) to US\$16 million (Toronto). ${ }^{1630}$ Estimates vary by level of abatement effort and assumptions regarding inclusion/exclusion of cost components associated with abatement activities.

In the context of the expression put forth in the conceptual model, total direct public TPL abatement costs can be expressed as $\mathrm{C}_{\mathrm{TPL}}=\lambda \mathrm{TC}_{\mathrm{L}}$, where $\mathrm{TC}_{\mathrm{L}}$ is the total cost of aggregate litter abatement in the city. In this expression, it is important to emphasise that $\mathrm{C}_{\text {TPL }}$ is a direct cost. Direct costs of litter abatement will generally underestimate the total costs of litter because indirect costs can be substantial but generally more difficult to accurately measure. The impact of litter on businesses and tourism has been well documented. According to the Florida Litter Study, the typical business in Florida spends an average of more than US\$2400 per year to clean up litter. ${ }^{24}$ Of the businesses surveyed, $98 \%$ indicated that the presence of litter lowered property values and had a negative impact on business sales. Similarly, the connection between litter and tourism has been widely reported. ${ }^{16} 172022$ 34-36

Perhaps more importantly, the environmental impact of TPL appears to be substantial based on some recent studies, and indirect costs associated with environmental impact have the potential to be substantial given the estimated volume of TPL in the environment. Cigarette butts are designed to capture some of the chemicals present in cigarette smoke, which means that the typical used (or smoked) cigarette butt contains some combination of ammonia, formaldehyde, butane, acrylonitrile, toluene, benzene, alkaloid nicotine and many other chemicals. When burned, many of these chemicals form new compounds. ${ }^{11} 122729$ Several studies have found that cigarette butts represent a potent toxin to organisms, ecosystems and humans, the costs of which have the potential to be substantial given the volume of TPL in the environment. ${ }^{11} 1225-293738$

\section{Fee calculations}

In this section we consider two broad public policy approaches to devising fee structures to recoup the costs associated with TPL abatement. There are a number of feasible options to designing fee structures to correct externalities ${ }^{5}$; in this section we briefly discuss two options. In many states, existing tobacco tax collection systems offer a potential apparatus upon which to add an abatement fee. The first and perhaps most straightforward approach is to spread TPL abatement costs across all tobacco sales in the city, and assess a proportional fee to each sale such that the total fees collected at year's end equal total TPL abatement costs. Per-pack fees will increase the net price of cigarettes, thereby potentially decreasing sales due to the elasticity of demand for cigarettes ${ }^{39-45}$ and requiring an off setting adjustment to assure targeted fee revenue.

An alternative approach is to spread abatement costs across all sellers of tobacco products, based on an estimate of each seller's tobacco product sales volume in a given year. Sales volume data at the product code level can be obtained from the US Economic Census, and these data can generally be obtained for specific US cities. Sellers could be grouped into 'sales channels' (eg, grocery stores; liquor stores; convenience stores; etc) and abatement costs could be spread across sales channels in the city proportionately based on the 'contribution' of each sales channel to overall tobacco sales. Assuming that sellers will pass the fees onto consumers in the form of higher prices, elasticity may also need to be taken into account.

For both approaches, another important consideration is to adjust the 'packs sold' data to reflect in-migration and outmigration of sales. Cities will want to avoid assessing fees on its sellers for tobacco litter brought in from outside city limits, and the likewise cities will not want to collect fees from its sellers for tobacco that is carried out of the city and potentially littered elsewhere. A reasonable approach is to consider these effects as offsetting, but another approach would be to consider whether inflows might differ from outflows for certain cities.

\section{Case study: San Francisco}

In this section we summarise the experiences of the City of San Francisco to develop a 'maximum permissible' per-pack mitigation fee to recoup some of the costs the City incurs each year to clean up TPL. ${ }^{13}$ In the context of the conceptual model, the approach taken was to solve the expression $\mathrm{C}_{\mathrm{TPL}}=\lambda \mathrm{TC}_{\mathrm{L}}$, where $\mathrm{TC}_{\mathrm{L}}$ is the total cost of aggregate litter abatement in the City. The chosen fee structure was to spread the abatement costs across all tobacco sales in the City and assess a per-pack fee.

It is also important to note that at the time of this writing, the City of San Francisco was considering fees but facing a new hurdle in the recent statewide passage of Proposition 26, which would greatly restrict the ability of California cities and municipalities from imposing 'externality offset' fees of any kind. Thus, the experiences of San Francisco are reported here to illustrate one way the problem might be approached rather than a full accounting of the final process carried out by the City. In addition, the content of this section is based on the authors' observations and in no way reflects the ideas and opinions of the City of San Francisco.

To estimate $\mathrm{TC}_{\mathrm{L}}$, City departments were asked to report their total direct operating costs attributable to general litter management, collection and abatement. These costs were reported to be approximately US\$25 million in 2009, with the vast majority of costs incurred by the Department of Public Works (DPW). Abatement activities already covered under existing fee structures and programmes (eg, Public Utility Commission TPL costs, which are factored into PUC rate setting) were excluded.

The City conducted Street Litter Audits (SLAs) in 2007, 2008 and 2009. In 2008, the San Francisco Department of Environment reaudited the 2007 sites and added additional sites to strengthen the litter observations. ${ }^{46}$ An additional data collection method was added to field work activities during the April 2009 litter audit. ${ }^{47}$ The San Francisco Department of Environment requested that consultants examine 32 sites to observe all 
small litter and large litter of those sites. TPL was found to represent $22.5 \%$ of all litter in these sites, an estimate remarkably similar to the TPL shares reported in litter audits and cleanup projects conducted in other cities and beaches. ${ }^{7} 16$

Total TPL costs to the City were calculated by multiplying the TPL share of $22.5 \%$ by the total annual litter abatement cost of US\$25 million in 2009, resulting in a base TPL abatement cost estimate of US\$5.6 million. To this amount, the City elected to add costs associated with administering the fee and the costs of a public anti-littering campaign, which together raised the annual total costs to approximately US\$7 million.

The calculation of per-pack fees involved several steps. First, data on cigarette packs sold per capita in California were obtained from a variety of sources. ${ }^{48-50}$ The CDC reported a 'packs per capita' value of 31.8 for California. To verify, the 2007 California Health Interview Survey data were used to estimate smoking prevalence and the number of cigarettes typically smoked per day in San Francisco. These data show remarkably similar results, suggesting that 31.8 packs per capita was an appropriate estimate for the state and for San Francisco. Second, in order to convert the packs-per-capita data into a measure of packs purchased in San Francisco per annum, data were adjusted for the influx of daytime commuters and daytime and nighttime visitors and tourists. ${ }^{51-53}$ An assumption was made that commuter and tourist visitors to San Francisco purchase $50 \%$ of their cigarettes outside of San Francisco. The result was a net estimate of 30.6 million cigarette packs purchased in San Francisco in 2008 (in terms of cigarettes purchased in San Francisco, 30.6 million packs converts to 612220520 individual cigarettes). The commuter and visitor adjustment resulted in an $11 \%$ reduction in litter abatement costs.

The result was a total 'recoverable' TPL cost of approximately US\$6.5 million. When divided by the estimate of total packs consumed by San Franciscans, the result is a maximum permissible per-pack fee of approximately US\$0.22. In 2009, the City passed into law a US $\$ 0.20$ per pack fee to cover the costs of TPL abatement. The implementation of the fee has been the subject of considerable debate, including a lawsuit filed on behalf of one large tobacco manufacturer. In addition, the passage in California of Proposition 26 in 2010 requires a two-thirds supermajority vote in the California State Legislature to pass fees, levies, charges and tax revenue allocations that under the State's previous rules could be enacted by a simple majority vote. This legislation may affect some existing fees as well as the passage of future fees at the local level.

\section{DISCUSSION}

In this paper we have considered the use of fees to offset the negative externality posed by TPL, and put forth a basic framework through which to conceptualise the problem and calculate proportional fees. This work represents an initial effort that can provide a foundation to guide future research which can refine or replace our model. The recent experiences of San Francisco serve as a case study of one way to approach this policy issue. Though San Francisco was able to enact a per-pack fee, there were considerable methodological challenges along the way. Two challenges in particular warrant further discussion: (1) obtaining accurate litter abatement costs from City departments responsible for litter mitigation and (2) estimating the quantity of TPL.

The calculation of TPL abatement costs is highly dependent on the accuracy of reported total litter abatement costs, but there are few external sources available to assess the validity of the City's reported US\$25 million total litter abatement costs. One way to verify the results is to compare the reported litter costs to Annual Reports from the individual departments. Though these reports do not disaggregate litter abatement costs, the reports support a comparison of total annual department costs relative to reported litter costs. The DPW's total annual operating costs in 2009 were US $\$ 171304668,{ }^{54}$ which implies that the US\$25 million total litter abatement estimate represents $14 \%$ of the department's budget and is $64 \%$ of the DPW's reported costs for 'street environmental services' of US\$39 million. The latter proportion seems high, but again there are no appropriate comparison benchmarks for these kinds of data.

Another approach to assessing the validity of the estimates is to compare to other reported litter abatement costs. Putting aside the added administrative and campaign fees added by San Francisco, the calculated cost of TPL abatement of US\$5.6 million is high relative to other reported data. According to one survey-based calculation, ${ }^{30}$ the average per-capita costs of general litter abatement for cities with populations larger than 100000 population was US\$2.91, or about US\$2.4 million for a city the size of San Francisco. Applying the same TPL weight observed in San Francisco litter audits (22.5\%), the City's expected TPL abatement costs would be only about US\$540 000 . However, this benchmark is based on an average level of abatement effort. There is likely to be high variation in levels of abatement effort and costs by city. San Francisco is one of the top 10 visitor destinations in the country, hosting $9 \%$ of all overseas travellers to the US and coming fifth in a ranking of 56 large US cities. ${ }^{55}$ The City's 15.4 million annual visitors represent nearly 20 times its resident population and generate close to US\$8 billion in economic activity. ${ }^{51}$ The City's visitor and tourism orientation is likely to encourage greater attentiveness to environmental hygiene.

Another limitation of the analysis is quantifying TPL. In this study we discuss San Francisco's use of litter surveys that count quantity of litter. Discussions with the departments responsible for litter mitigation indicated that quantity, rather than volume or weight, was the most important driver of cost. However, we were not able to find external sources to support the 'quantity-cost' relationship.

A further question is whether these fees would pass a regulatory cost-benefit analysis. ${ }^{56-58}$ The results of a cost-benefit analysis would depend on several factors. Scope and perspective are likely among the most important factors. A broader scope of TPL costs would include indirect costs, such as harm to businesses, tourism, ecosystems and human health. No studies have undertaken a full accounting of these costs, but early studies suggest the negative effects of TPL could be substantial. Another important cost-benefit factor would be a decrease in demand associated with the price increase. This would bring in to the analysis the attributable costs of smoking-related illnesses, the costs of which are substantial. ${ }^{59}$

Finally, it is unclear how this approach to fee setting is applicable to other jurisdictions. Similar to the legal impediments imposed by laws such as California's Proposition 26, other cities, states and countries may have laws that restrict the use of externality-based fees. In addition, ex-US applications of this methodology would require data analogous to the various US government sources described above.

\section{Conclusions}

Tobacco litter abatement costs to cities are substantial, even when the costs of toxicity and reduced tourism are excluded. According to the literature, public litter abatement costs for 


\section{What this paper adds}

- Several studies have identified innovative policies to address the myriad negative externalities associated with tobacco consumption. One policy area in which there is little existing research is tobacco litter mitigation. Tobacco litter is toxic, slow to decompose, costly to manage, and growing in volume as indoor smoking bans move smokers outside.

- This study describes one way to address the problem of tobacco litter: offsetting the costs by levying fees on tobacco sellers. We describe the recent experiences of San Francisco, California, where tobacco litter fees have been implemented for the past year. This paper puts forth a framework and methodology that can be applied to other jurisdictions interested in recouping the costs of tobacco litter.

large US cities range from US\$3 million to US\$16 million per year. $^{16} 30$ TPL typically comprises between $22 \%$ and $36 \%$ of all visible litter, ${ }^{16} 3060$ implying that total public TPL direct abatement costs range from about US $\$ 0.5$ million to US\$6 million for a city the size of San Francisco. The costs of mitigating the negative externalities of TPL in a city the size of San Francisco can be offset by implementing a fee ranging of approximately US $\$ 0.20$ per pack. Greater efforts should be made to address the problems associated with TPL, and cities should consider implementing fees to offset the costs of the negative externality.

Acknowledgements We thank Paul Ledesma, who at the time the research was completed served as the City Government Zero Waste Coordinator in the City and County of San Francisco Department of the Environment.

Funding This work was funded by the City of San Francisco.

Competing interests None.

Provenance and peer review Not commissioned; externally peer reviewed.

\section{REFERENCES}

1. Coase RH. The Firm, the Market and the Law. Chicago, IL: The University of Chicago Press, 1988

2. Diamond PA. Consumption Externalities and Imperfect Corrective Pricing. The Bell Journal of Economics and Management Science 1973:4:526-38.

3. Hines JR. Taxing consumption and other sins. J Econ Perspect 2007;21:49-68

4. USDA. Tobacco Outlook. Electronic Outlook Report from the Electronic Research Service TBS-263. Washington, DC: United States Department of Agriculture, 2007.

5. Novotny TE, Zhao F. Consumption and production waste: another externality of tobacco use. Tob Control 1999:8:75-80.

6. Bator R, Bryan A, Schultz PW. Who Gives a Hoot? Intercept Surveys of Litterers and Dosposers. Environ Behav. Published online first 19 Oct 2010. doi:10.1177/ 0013916509356884

7. Ocean Conservancy. A Rising Tide of Ocean Debris: Report of the 2009 International Coastal Cleanup. Washington, DC: Ocean Conservancy, 2009.

8. Atwater KM. Anti-littering campaign targets cigarette butts. Government Product News 2005; $44: 3$

9. Jeff H. The week; tobacco trash dominates Haul at State Shoreline. New York Times 2006:2.

10. Johnson J. Where there's smoke, there's litter. Waste News 2006;11:36.

11. Moriwaki H, Kitajima S, Katahira K. Waste on the roadside, "poi-sute" waste: Its distribution and elution potential of pollutants into environment. Waste Manag 2009;29:1192-7.

12. Novotny TE, Lum K, Smith E, et al. Cigarette butts and the case for an environmental policy on hazardous cigarette waste. Int $J$ Res Public Health 2009:6:1691-705.

13. Kaufman L, Cullotta KA, Wollan M, et al. Cigarette butts: tiny trash that piles up. New York Times 2009:12.

14. Marais M, Armitage N, Pithey S. A study of the litter loadings in urban drainage systems-methodology and objectives. Water Sci Technol 2001;44:99
15. Al-Hamdan AZ, Nnadi FN, Romah MS. Performance reconnaissance of stormwate proprietary best management practices. J Environ Sci Health A Tox Hazard Subst Environ Eng 2007:42:427-37.

16. Keep America Beautiful, Beck RW. Literature Review-Litter: A Review of Litter Studies, Attitude Surveys, and Other Litter-Related Literature. Stamford, CT: Keep America Beautiful \& R.W. Beck, 2007.

17. BBC News. Litter Rubbishes Tourism Trade. BBC News 2004. http://newsvote.bbc co.uk.

18. Derraik JGB. The pollution of the marine environment by plastic debris: a review. Mar Pollut Bull 2002:44:842-52.

19. Klein EG, Forster JL, McFadden B, et al. Minnesota Tobacco-Free Park Policies: Attitudes of the General Public and Park Officials. Nicotine \& Tobacco Research: Oxford University Press/UK, 2007:49-55.

20. Kozak M, Bigne E, Gonzalez A, et al. Cross-cultural behaviour research in tourism a case study on destination image. In: Crouch GI, Perdue RR, Timmermans HJP, et al, eds. Consumer Psychology of Tourism, Hospitality, and Leisure: Volume 3. Cambridge MA: CABI Publishing, 2004

21. Leous JP, Parry NB. Who is responsible for marine debris? the international politics of cleaning our oceans. J Int Affairs 2005;59:257-69.

22. Lundie S, Dwyer L, Forsyth P. Environmental-Economic Measures of Tourism Yield. Journal of Sustainable Tourism: Multilingual Matters 2007:503-19.

23. Moore CJ. Synthetic polymers in the marine environment: a rapidly increasing, longterm threat. Environ Res 2008:108:131-9.

24. Butterfield C, Myers D, Hilker E, et al. The Florida Litter Study: Economic Impacts of Litter on Florida's Businesses. Gainesville, FL: Florida Center for Solid and Hazardous Waste Management (for the Florida Legislature and the Florida Department of Environmental Protection, 1999

25. Centers for Disease Control and Prevention. Ingestion of cigarettes and cigarette butts by children. MMWR Morbid Mortal Wkly Rep 1997;46:125.

26. Ellaway A, Morris G, Curtice $\mathrm{J}$, et al. Associations between health and different types of environmental incivility: a Scotland-wide study. Public Health 2009:708-13.

27. JAMA. Ingestion of cigarettes and cigarette butts by children-Rhode Island, January 1994-July 1996. JAMA 1997:277:785

28. Micevska T, Warne MS, Pablo F, et al. Variation in, and causes of, toxicity of cigarette butts to a cladoceran and microtox. Arch Environ Contam Toxicol 2006:50:205-12.

29. Novotny TE, Hardin SN, Hovda LR, et al. Tobacco and cigarette butt consumption in humans and animals. Tob Control 2011;20(Supp 1):i16-i19.

30. Kep America Beautiful, MSW Consultants. National Visible Litter Survey and Litter Cost Study. New Market, MD: Keep America Beautiful/Mid-Atlantic Solid Waste Consultants, 2009.

31. Schultz PW, Large LB, Tabanico J, et al. Littering Behavior in America: Results of a National Study. San Marcos, CA: Action Research/Keep America Beautiful, 2009.

32. City of Baltimore. The Cost of Litter. Cleaner Greener Baltimore 2010.

33. Pitfield J, Rathbone G. City of Toronto Launches Litter Prevention Program. City of Toronto 2003

34. New Scientist. Graffiti and litter lead to more street crime. New Scientist 2008:199:17.

35. Selby M. Understanding Urban Tourism: Image, Culture, and Experience. New York NY: I.B. Tauris \& Co Ltd, 2004

36. Smith E. On the Jersey Shore, Business Crumbles Like a Sand Castle. BusinessWeek 1987. cover story

37. Krisberg K. Cigarette Butt Pollution Project takes aim at tons of toxic waste. Nation's Health 2009;39:28.

38. Register K. Cigarette Butts as Litter: Toxic as Well as Ugly? Underwater Naturalist Bulletin of the American Littoral Society. 2000;25. http://www.cigarettelitter.org (accessed 28 May 2009).

39. Ahmad S, Franz GA. Raising taxes to reduce smoking prevalence in the US: a simulation of the anticipated health and economic impacts. Public Health 2008; 122:3-10.

40. Carpenter C, Cook PJ. Cigarette taxes and youth smoking: new evidence from national, state, and local Youth Risk Behavior Surveys. J Health Econ 2008;27:287-99

41. Chaloupka FJ, Pacula RL. Sex and race differences in young people's responsiveness to price and tobacco control policies. Tob Control 1999;8:373-7.

42. Franz GA. Price effects on the smoking behaviour of adult age groups. Public Health 2008:122:1343-8.

43. Gallus S, Schiaffino A, La Vecchia C, et al. Price and cigarette consumption in Europe. Tob Control 2006:15:114-19.

44. Lewitt EM, Coate D. The potential for using excise taxes to reduce smoking $J$ Health Econ 1982;1:121-45.

45. Zhang B, Cohen J, Ferrence $\mathrm{R}$, et al. The impact of tobacco tax cuts on smoking initiation among Canadian young adults. Am J Prev Med 2006;30:474-9.

46. HDR. The City of San Francisco Streets Litter Re-Audit. Omaha, NE: HDR Engineering/ Brown, Vence \& Associates, Inc/MGM Management, 2008.

47. McKenney M. Preliminary Report: San Francisco Super Site Data 2009. Osoyoos, BC, Canada: MGM Management \& HDR Engineering, 2009.

48. Centers for Disease Control and Prevention. 2008 Tobacco Control Highlights. California. CDC State Tobacco Activities Tracking and Evaluation (STATE) System. Atlanta, GA: U.S. Centers for Disease Control and Prevention, 2009.

49. Centers for Disease Control and Prevention. Behavioral Risk Factor Survey. Atlanta, GA: U.S. Centers for Disease Control and Prevention, 2010. 
50. Centers for Disease Control and Prevention. Online access to U.S. National Health Interview Survey. U.S. Centers for Disease Control and Prevention, 2010. http://www.ihis.us/inis/index.shtml.

51. San Francisco Convention and Visitors Bureau. San Francisco Fact Sheet. San Francisco, CA, 2010.

52. US Bureau of the Census. Table 1: Leading Places on Percent Change in Daytime Population, by Size (Total Resident Population). Estimated Daytime Population and Employment-Residence Ratios: 2000. Washington, DC: U.S. Bureau of the Census, 2000.

53. US Bureau of the Census. PHC-T-40: Estimated Daytime Population and EmploymentResidence Ratios: 2000. Washington, DC: U.S. Bureau of the Census, 2000

54. San Francisco Department of Public Works. San Francisco Department of Public Works: Fiscal Year 2009-2010 Annual Report. San Francisco, CA, 2010.

55. US Department of Commerce. Overseas Visitors to Select U.S. Cities/Hawaiian Islands, 2001-2002. Washington, DC: U.S. Department of Commerce, Office of Travel and Tourism Industries, 2003.
56. Farrow S, Toman M, Schmitz A, et al. Using Benefit-Cost Analysis to Improve Environmental Regulation. Applied Benefit-Cost Analysis: Elgar Reference Collection. International Library of Critical Writings in Economics. vol. 231. Cheltenham, U.K., Northampton, MA: Elgar, 2008:405-17.

57. Greenstone M, Balleisen EJ, Moss DA. Effective Regulation through Credible CostBenefit Analysis: The Opportunity Costs of Superfund. Government and Markets: Toward a New Theory of Regulation. Cambridge: Cambridge University Press, 2010:52-91.

58. Hahn RW, Tetlock PC. Has economic analysis improved regulatory decisions? J Econ Perspect 2008;22:67-84.

59. Max W, Rice DP, Sung HY, et al. The economic burden of smoking in California. Tob Control 2004;13:264-7.

60. HDR. The City of San Francisco Streets Litter Re-Audit 2009. San Francisco, CA: HDR/ Brown, Vence \& Associates, Inc. and MGM Management, 2009.

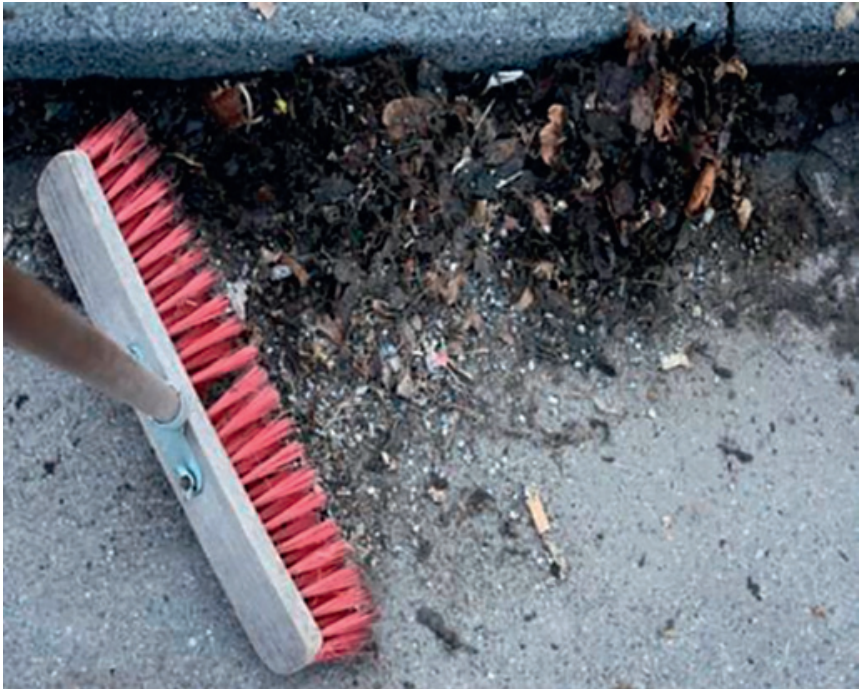

